For juvenile diversion programs to reach their goals of reducing labeling, social control, and costs, they must serve a population that is diverted from processing in the justice system. Some evaluations imply that these goals conflict with the goal of reducing recidivism because diversion programs are most effective with youths who have the least serious offense histories. The present study examines the issue using data for a broad range of outcomes from three programs that randomly assigned youths to treatment and control groups. Data analysis indicated no relationship between program effectiveness and the seriousness of clients' offense histories.

\title{
OFFENSE HISTORY AND JUVENILE DIVERSION
}

\author{
D. WAYNE OSGOOD
}

University of Michigan

$\mathcal{T}$

he present study concerns the relation between clients' offense histories and the effectiveness of diversion programs for juvenile offenders. These programs are intended as community-based alternatives to formal justice dispositions, and the type of clients they serve is inextricably related to their mission. This mission was summarized by Palmer and Lewis (1980), who articulated five goals that have been widely held for juvenile diversion programs: (a) to avoid labeling, (b) to reduce social control and coercion, (c) to reduce costs, (d) to reduce recidivism, and (e) to provide services.

Diversion programs' success at reaching three of these goals is dependent on serving a client population that would otherwise have received formal dispositions from the justice system. The programs are

\footnotetext{
AUTHOR'S NOTE: An earlier version of this article was presented at the 1982 convention of the American Psychological Association. This research was funded by the National Institute of Juvenile Justice and Delinquency Prevention, grants 77-N1-99-0011, 77-JN99-0009, and 78-JA-AX-0037.
}

EVALUATION REVIEW, Vol. 7 No. 6, December 1983 793-806

@ 1983 Sage Publications, Inc. 
to avoid the labeling, social control, and costs of justice system processing by removing their clients to a community-based setting. This is not possible if the clients were never in jeopardy of such processing. Thus, these three goals are not just compatible but interrelated.

The goal of providing services might appear somewhat at odds with the preceding three. The cost of services reduces potential savings, and any social service may entail some labeling and social control. The premise behind diversion programs is that the costs, labeling, and social control of community-based services will be less than services provided by the justice system. Furthermore, youths at greater risk of formal dispositions would, presumably, have greater need for services. Thus, choosing a client population with a more serious history of offenses is quite consistent with the fourth goal as well.

Findings from some evaluations of juvenile diversion have, however, raised the possibility that the goal of reducing recidivism is at odds with the others, and that issue is the concern of this article. Quay and Love (1977) and Lipsey et al. (1981) report that the programs they investigated reduced recidivism only for clients with the least prior contact with the justice system. As Lipsey et al. document for their program, such clients are precisely the ones who would have been released if the diversion program had not been available. Thus, reducing recidivism would mean giving up on reducing labeling, social control, and justice system costs.

There is also evidence that contradicts those two studies. Palmer and Lewis (1980) found diversion to reduce recidivism for offenders with one prior arrest, but not for those with either no prior record or at least two prior arrests. On the other hand, there was no relation at all between prior arrests and program effectiveness in a study by Lincoln et al. (1981).

In addition to policy implications, there is a theoretical reason to be interested in the relation between offense history and program effectiveness. A primary argument for expecting diversion to affect recidivism is that stigma from the justice system leads to delinquent behavior, and this stigma would be avoided by basing services in the community. If this reasoning is correct, diversion programs would have the most impact on offenders who are at greatest risk of being stigmatized. These would be youths whose previous delinquent involvement has not been serious enough to provoke stigmatizing responses, but has been serious enough that the offender is at risk of formal sanctions for the most recent offense. 
The present study uses data from the national evaluation of diversion programs conducted by the Behavioral Research Institute. This evaluation offers an opportunity for a much more thorough examination of offense history and program effectiveness than prior efforts. First, youths were randomly assigned to diversion and control conditions, so there is a firm basis for inference about program effects. Second, the study includes programs in three cities, and the justice systems in those cities have very different criteria for case dispositions. Thus one can determine if local standards for involving formal sanctions affect which offenders would be most helped by diversion. Third, in addition to arrest records, the data include a broad range of outcome measures collected by personal interviews. Not only does this permit broadening the assessment of outcome beyond recidivism, it also allows one to define the seriousness of prior delinquent involvement in terms of self-reported behavior as well as prior arrests.

\section{METHODS}

The diversion programs, research design, data collection, and measures are described in detail in the final report of the national evaluation (Dunford et al., 1981), so the present description will be more limited.

\section{RESEARCH SITES}

Midwest. A department within city government operated this diversion project in cooperation with the city police department. The project included two separate service programs. In the first program, professional social workers hired by the police department provided crisis intervention that was limited to one month. The second service program was administered by the city and employed a longer-term case advocacy model. For both programs, the point of diversion was the juvenile division of the city police department. The typical client had been arrested one or more times prior to the offense that led to participating in the study.

Upper South. A private nonprofit organization housed this diversion project. The project functioned as a brokering agency, receiving 
referrals from juvenile court intake, interviewing youths to determine service placements, and then monitoring services delivered by a variety of community agencies. The most prevalent service was counseling, either individual or family. The next most frequent was recreation, and some clients received employment or educational assistance. Half of the youths placed in the assignment pool had been previously arrested.

Lower South. This diversion project was also operated by a private nonprofit organization, and it brokered services through community agencies. Unlike the other diversion projects, each client contracted for a specific amount and type of service, depending only on the service agency chosen. The project placed less emphasis on counseling than the other projects and more emphasis on recreational activities.

The head of the local state attorney's office was responsible for determining which cases would be placed in the pool for random assignment. The pool was predominantly first-time misdemeanants, though minor felony cases were occasionally included. It should be noted that most first-time misdemeanants faced court hearings in this county.

\section{RESEARCH DESIGN AND DATA COLLECTION}

At each of the three research sites, arrested youths were randomly assigned to either outright release, referral to a diversion program, or normal processing by the justice system. Though not all youths referred for services at the diversion programs actually received them, a large proportion received at least some services beyond initial intake ( $85 \%$ for midwest, $73 \%$ for upper south, and $71 \%$ for lower south). All cases assigned to the justice system proceeded to the next stage of processing (court intake for midwest and upper south, court hearing for lower south), but ultimate dispositions varied widely. At the midwest site, $24 \%$ of the youths assigned to normal processing were adjudicated delinquent and placed under court supervision, as was true of $34 \%$ of this group for the upper south site and $45 \%$ for the lower south site. Youths in the release condition were processed no further in the justice system, at least not for the offense that placed them in the study. At each site a small proportion ( $5 \%$ to $10 \%$ ) of this group reported that they had obtained services on their own from a community-based agency.

Youths participating in the study were interviewed soon after random assignment and again twelve months later. Court and police records 
were obtained for prior arrests as well as any arrests in the twelve months subsequent to assignment. A total of over 1300 youths participated in the study. Sample sizes at the three sites ranged from approximately 75 to 200 cases per group.

The interview assessed a broad range of outcomes pertinent to diversion programs. It included several measures of perceived stigma (feelings that friends, parents, and teachers considered one delinquent, emotionally disturbed, or comforming) and an extensive measure of self-reported delinquency. Additional measures were based upon the integrated strain-control theory of delinquency (Elliott et al., 1979), and were originally developed for the National Survey of Youth (Elliott and Ageton, 1980). In accord with this theory, the measures focused on bonds to the conventional social order (e.g., normlessness and importance of conventional goals), strains on such bonds (e.g., perceived stigma and social isolation), and social learning (delinquency of peers).

The comparability of the groups that resulted from the assignment process has been thoroughly examined by analysis of measures taken at the time of assignment (Dunford et al. 1981). Results indicated that procedures at these three sites resulted in comparable groups. A fourth site was eliminated from the present analysis because it appeared likely that assignment was biased in the direction of referring the more serious cases to normal justice processing.

\section{RESULTS}

The aim of the present study was to determine if the impact of diversion programs on their clients depends on the degree of clients' prior involvement in delinquency. Our analysis approach was to test for differential effectiveness by the significance of the interaction term for offense history and treatment condition (release, diversion or justice processing). A lack of significance indicates that any difference in the effectiveness of diversion for one group rather than another is no larger than can be expected by chance. The dependent variables were either recidivism or the outcome measures from the interview. In each case, two measures of offense history were used.

The first measure of offense history was prior arrest. At the midwest and lower south sites, respondents were divided into three groups: those with no arrests prior to the offense that led to their participation in the study, those with one prior arrest, and those with two or more prior 
arrests. Because very few respondents at the lower south site had more than one prior arrest, they were divided into those with prior arrests and those without.

Self-reported delinquency for the six months prior to the initial interview was the basis for the second measure of offense history. The self-report method offers a means of assessing delinquent behavior that does not reflect labeling by the justice system and that goes beyond that small proportion of offenses that comes to the attention of the authorities. Cases at all three sites were divided into three groups on the basis of their involvement in non-drug-related offenses. ${ }^{1}$ The cutoff points for the groups were chosen to segment the entire sample into thirds, so the proportions for the individual sites varied somewhat.

\section{RECIDIVISM}

Log-linear analysis was used to test for an interaction of offense history and treatment condition in their effects on recidivism. We defined recidivism as an arrest for a felony or misdemeanor during the 12 months following random assignment. ${ }^{2}$ The results of this analysis appear in Tables 1 and 2.

When offense history was defined in terms of prior arrests, the interaction effects approached significance at the midwest site $\left(\mathrm{X}^{2}=\right.$ 10.37, $\mathrm{df}=6, \mathrm{p}=11)$ and upper south site $\left(X^{2}=7.93, \mathrm{df}=4, \mathrm{p}=.09\right)$, but not the lower south site $\left(X^{2}=.01, d f=2, p>.50\right)$. While such marginal effects hardly justify strong inferences, close examination of Table 1 for possible trends is in order. As the significance test would lead one to expect, the relation of treatment condition to recidivism at the lower south site is quite constant regardless of prior arrests.

Patterns at the other sites are more complex. At both, recidivism among those with one prior arrest is lowest for the diversion group, but there the similarity ends. For youths with no prior arrests, diversion is the most successful treatment condition at the midwest site, but the least successful condition at the upper south site. This pattern is virtually reversed for youths with two or more prior arrests.

The relative success of diversion for the group with one prior arrest is consistent with the findings of Palmer and Lewis (1980). Nevertheless, the inconsistency of the overall pattern of findings renders this similarity unconvincing. Additional evidence is needed before reaching conclusions.

The second analysis of recidivism used self-reported delinquency as a measure of offense history. The log-linear analysis yielded insignificant 
TABLE 1

The Relation of Treatment Condition and Prior Arrests to Percentage Recidivism

\begin{tabular}{|c|c|c|c|c|}
\hline \multirow[t]{2}{*}{ Treatment Condition } & \multicolumn{4}{|c|}{ Prior Arrests } \\
\hline & None & One & Two or More & $N$ \\
\hline \multicolumn{5}{|l|}{ Midwest } \\
\hline Release & 36 & 53 & 55 & 84 \\
\hline Diversion & 29 & 30 & 63 & 200 \\
\hline Justice Processing & 48 & 41 & 45 & 89 \\
\hline \multicolumn{5}{|l|}{ Upper South } \\
\hline Release & 19 & 35 & 48 & 236 \\
\hline Diversion & 30 & 25 & 40 & 177 \\
\hline Justice Processing & 15 & 34 & 27 & 136 \\
\hline Lower South & None & \multicolumn{2}{|c|}{ One or More } & $N$ \\
\hline Release & 15 & \multicolumn{2}{|c|}{18} & 147 \\
\hline Diversion & 18 & \multicolumn{2}{|c|}{22} & 182 \\
\hline Justice Processing & 17 & \multicolumn{2}{|c|}{21} & 147 \\
\hline
\end{tabular}

NOTE: Entries are percentages of each group who were arrestd for a non-status offense within one year of assignment to the treatment condition.

interactions between offense history and treatment condition at all three sites (for midwest, $\mathrm{X}^{2}=6.41, \mathrm{df}=6, \mathrm{p}=.38$; for upper south, $\mathrm{X}^{2}=.58, \mathrm{df}=$ $4, \mathrm{p}>.50$; for lower south, $\mathrm{X}^{2}=.37, \mathrm{df}=4, \mathrm{p}>.50$ ). A review of Table 2 reveals no striking effects. In fact, the weak trends that appear are quite different from those in Table $1 .{ }^{3}$

In sum, the analysis of recidivism offers only very weak evidence of differential treatment effectiveness. There were no statistically significant interaction effects. The two cases in which interaction effects approached significance are difficult to interpret, but give some indication that diversion may be most effective for youths with one prior arrest. The opposite trend appeared in relation to prior self-reported delinquency.

Treatment effects for youths with the least prior delinquency are of special interest because reports of greater effectiveness of diversion for that group indicated a potential conflict between the goal of reducing recidivism and other goals for diversion. Tables 1 and 2 reveal that diversion was as often less successful as more successful with this class of offenders.

\section{OTHER OUTCOME MEASURES}

The interview contained a large number of measures covering selfreported delinquency, perceived stigma, and social adjustment. In order 
TABLE 2

The Relation of Treatment Condition and Prior Self-Reported Delinquency to Percentage Reported Decidivism

\begin{tabular}{|c|c|c|c|c|}
\hline \multirow[t]{2}{*}{ Treatment Condition } & \multicolumn{4}{|c|}{ Prior Self-Reported Delinquency } \\
\hline & Low & Medium & High & $N$ \\
\hline \multicolumn{5}{|l|}{ Midwest } \\
\hline Release & 44 & 39 & 56 & 80 \\
\hline Diversion & 31 & 48 & 46 & 181 \\
\hline Justice Processing & 39 & 32 & 58 & 84 \\
\hline \multicolumn{5}{|l|}{ Upper South } \\
\hline Release & 28 & 25 & 36 & 234 \\
\hline Diversion & 23 & 28 & 37 & 176 \\
\hline Justice Processing & 18 & 20 & 31 & 116 \\
\hline \multicolumn{5}{|l|}{ Lower South } \\
\hline Release & 11 & 19 & 19 & 147 \\
\hline Diversion & 16 & 19 & 24 & 182 \\
\hline Justice Processing & 14 & 19 & 24 & 147 \\
\hline
\end{tabular}

NOTE: Entries are percentages of each group who were arrestd for a non-status offense within one year of assignment to the treatment condition.

to maximize the likelihood of detecting significant effects without capitalizing on chance, analysis was limited to 13 summary measures ${ }^{4}$ that most reliably capture the major themes of the interview. Multivariate analysis of covariance was used for significance tests since this technique provides an omnibus test for effects on an entire set of dependent variables. In order to increase the power of the analysis, we also used as covariates pretest measures of all outcome variables as well as age, sex, and ethnicity. ${ }^{5}$

There were no significant interactions between prior arrests and treatment condition in the multivariate analysis (mid west, $\mathrm{p}=.42$; upper south, $p=.50$; lower south, $p=.21$ ). The univariate tests also offer little indication of differential effectiveness. Of the 13 dependent variables, there was one for which $\mathrm{p}<.05$ at the midwest site, one at the upper south site, and two at the lower south site. All of these cases involved different variables, and there was little similarity in the pattern of the effects.

Results concerning differential effectiveness on the basis of prior self-reported delinquency were essentially the same. None of the multivariate tests for interaction effects were significant (midwest, $\mathbf{p}=$ 
.69 ; upper south, $\mathrm{p}=.29$; lower south, $\mathrm{p}=.15$ ). Out of the 39 univariate tests involved, none were significant with $\mathrm{p}<.05$.

By broadening the definition of program outcome to include many variables generally thought to be relevant to delinquent behavior, we obtain no additional evidence that diversion programs are more effective for one type of offender than another. For comparison to the results for recidivism, Tables 3 and 4 present the means for self-reported delinquency. One nominally significant finding is represented in those tables, the interaction of treatment condition and prior arrests at the upper south site (Table 3 ). Any effect there seems due to diversion being less successful for youths who had any prior arrests. The relative success of diversion for youths with one prior arrest that was suggested by the analysis of recidivism does not appear for self-reported delinquency. Furthermore, there is no support for the contention that diversion is most successful at reducing delinquency for youths with the least serious offense history. If anything, there are particularly small differences in the effectiveness of the treatment conditions for this group.

\section{DISCUSSION}

The present study has subjected the issue of offense history and the effectiveness of diversion programs to a much more thorough examination than any prior study and has found no convincing evidence of any relation between the two. The analysis included programs at three sites, all of which used random assignment to assure comparability of treatment groups. While other studies have defined outcomes only in terms of recidivism, the present study included a broad range of measures that bear on delinquency.

\section{INTERPRETING PRIOR RESEARCH}

A review of the three studies that report differential effectiveness is useful in order to reconcile the present findings with them. For two of the studies, the reason that conclusions are at odds with the present study appears to be the choice of statistical methods. We have relied on tests of interaction effects, which are a direct significance test for variation in treatment effectiveness across classes of offenders. Lewis and Palmer (1980) and Lipsey et al. (1981) reach their conclusions on the basis of testing effectiveness separately for each class of offenders. 
TABLE 3

Mean Self-Reported Delinquency* by Treatment Condition and Prior Arrests

\begin{tabular}{|c|c|c|c|c|}
\hline \multirow[t]{2}{*}{ Treatment Condition } & \multicolumn{4}{|c|}{ Prior Arrests } \\
\hline & None & One & Two or More & $N$ \\
\hline \multicolumn{5}{|l|}{ Midwest } \\
\hline Release & 1.01 & 1.30 & 1.09 & 70 \\
\hline Diversion & .89 & 1.52 & 1.31 & 151 \\
\hline Justice Processing & 1.10 & 1.19 & 1.26 & 71 \\
\hline \multicolumn{5}{|l|}{ Upper South } \\
\hline Release & .91 & 1.12 & .71 & 204 \\
\hline Diversion & .89 & 1.00 & 1.27 & 162 \\
\hline Justice Processing & .92 & .84 & .87 & 101 \\
\hline Lower South & None & \multicolumn{2}{|c|}{ One or More } & $N$ \\
\hline Release & .99 & \multicolumn{2}{|c|}{1.10} & 129 \\
\hline Diversion & .89 & \multicolumn{2}{|c|}{.94} & 158 \\
\hline Justice Processing & .88 & \multicolumn{2}{|c|}{1.04} & 117 \\
\hline
\end{tabular}

*Scores are in an arbitrary metric and should not be interpreted as directly indicating the nuber of delinquent acts. See Note 1.

Separate significance tests may lead one to conclude that a treatment is effective for one group but not another when there was no significant interaction. In such a case the difference in effectiveness could be attributed to random error. This circumstance is likely when the treatment effect for the entire sample is of borderline significance, which is true of both of these studies.

A reanalysis of data presented in these two studies reveals that there was no significant relation of offense history to program effectiveness in either case. Subjecting the relevant data from Palmer and Lewis (1980: 95) to a log-linear analysis yielded insignificant interaction effects for non-status offenses $\left(X^{2}=2.02, d f=2, p=.36\right)$ as well as for all offenses combined $\left(\mathrm{X}^{2}=4.11, \mathrm{df}=2, \mathrm{p}=.13\right)$. Lipsey et al. (1981) interpret two of their analyses as indicating greater treatment effectiveness for less serious cases. Nevertheless, interaction terms from log-linear analyses were insignificant for both their tie-breaking randomization design ( $p$. $293, \mathrm{X}^{2}=.82, \mathrm{df}=1, \mathrm{p}=.36$ ) and their matched groups design (p. 296, $\mathrm{X}^{2}$ $=.28, \mathrm{df}=1, \mathrm{p}>.50)$.

The two remaining studies of offense history and the effectiveness of diversion programs used random assignment and tested for differential treatment effectiveness by interaction terms. Thus, they should be 
TABLE 4

Mean Self-Reported Delinquency* by Treatment Condition and Prior SelfReported Delinquency

\begin{tabular}{lcccc}
\hline \multicolumn{1}{c}{ Treatment Condition } & \multicolumn{4}{c}{$\begin{array}{c}\text { Prior Self-Reported } \\
\text { Delinquency }\end{array}$} \\
& Low & Medium & High & $N$ \\
\hline Midwest & & & & \\
$\quad$ Release & .72 & 1.04 & 1.48 & 71 \\
$\quad$ Diversion & .66 & .91 & 1.57 & 152 \\
$\quad$ Justice Processing & .66 & .91 & 1.57 & 152 \\
\hline Upper South & & & & \\
$\quad$ Release & .47 & .77 & 1.40 & 209 \\
$\quad$ Diversion & .47 & 1.07 & 1.24 & 162 \\
$\quad$ Justice Processing & .52 & .84 & 1.34 & 101 \\
\hline Lower South & & & & \\
$\quad$ Release & .59 & 1.15 & 1.66 & 129 \\
$\quad$ Diversion & .63 & .84 & 1.63 & 158 \\
$\quad$ Justice Processing & .55 & 1.15 & 1.36 & 118 \\
\hline
\end{tabular}

*Scores are in an arbitrary metric and should not be interpreted as directly indicating the number of delinquent acts. See note 1 .

relatively strong studies. Lincoln et al (1981) did not find a differential treatment effect, but Quay and Love (1977) did. The program studied by Quay and Love was found to be much more successful with the least serious offenders. In their case these youths did not arrive at the diversion program as the result of an arrest, but by informal referrals, often from outside the justice system altogether. What is striking about Quay and Love's findings is not that recidivism among informal referrals treated by the diversion program is low (24\%); a low rate would be expected for a group with no arrest history. Rather, the recidivism rate for informal referrals in the control condition is remarkably high (64\%), far higher than the control group of youths who had been arrested on delinquency charges (36\%). It seems unwise to interpret this result as a success for the diversion program since the effect seems to lie with the control condition.

Considering the results from the four prior studies in addition to the present study, there is only one case of a significant effect indicating that the effectiveness of diversion programs depends on clients' offense histories. That study is less than convincing, and the pattern of results for the remaining studies varies widely. Therefore, it appears quite safe to conclude that the success of diversion programs at reducing 
delinquent behavior is unrelated to the offense histories of the youths they serve.

\section{IMPLICATIONS OF THE FINDINGS}

Differential treatment effectiveness is an important issue in the evaluation of social services. It would be foolish to presume that the same program would be helpful to everyone. Nevertheless, the search for differential treatment effects must be based on sound statistical techniques. In any given sample, a treatment program will be more successful for some groups than for others, if only by chance. One must beware of treating these random fluctuations as a basis for choosing future target populations. The extremely divergent findings of the studies reviewed above illustrates the danger of too willingly rejecting the null hypothesis and the importance of replication across studies.

In the case of offense history and the effectiveness of diversion programs, some evaluations seemed to have the profound implication that the goal of reducing recidivism was inconsistent with the goals of reducing labeling, social control, and justice system costs. This is a very serious matter, since research has clearly shown that the vast majority of diversion programs have sacrificed these latter goals in favor of serving a less serious, but more available, population of offenders (Klein, 1979). The present study demonstrates that this sacrifice cannot be excused by greater success at modifying delinquent behavior.

The cumulative results indicate that diversion programs are justifiable only if they serve a population that would otherwise receive formal dispositions from the justice system. This will not impede efforts to reduce recidivism. Whether or not diversion programs reduce recidivism for any class of offenders is a matter of debate (see Klein, 1979, for a brief discussion). There is, however, evidence that diversion programs are less oriented to social control and coercion and more oriented to serving clients' needs than justice agencies (Osgood and Weichselbaum, forthcoming). These benefits can only be obtained if diversion programs are truly used as an alternative to formal dispositions in the justice system.

The results of the present study also fail to support the logic of labelling theory. From this theory one would predict greater effectiveness of diversion programs for youths most at risk of formal dispositions from the justice system. This was not the case. Though the present study does not constitute a critical test of labelling theory, it does contribute to a growing body of evidence against it (Gove, 1980). 


\section{NOTES}

1. A complex scoring procedure was used for the indices of self-reported delinquency, which is described in detail elsewhere (Dunford et al., 1981: 88-92). This procedure balanced the contribution of various items to the indices and minimized skewness, making the indices more amenable to standard statistical techniques. Common scoring procedures place undue emphasis on the least serious offenses because of their greater frequency. To avoid this phenomenon, items of similar seriousness were grouped into subscales that were empirically and conceptually cohesive. The indices actually used in analyses were combinations of these scales, each standardized to equalize its contribution to the total. Because the three subscales reflecting drug use (alcohol, marijuana, and hard drugs) were more highly related to one another than to other subscales, they were grouped into a separate index. The general delinquency index was composed of subscales for serious assault, minor assault, robbery, serious theft, minor theft, damaging property, and public disorder. Status offenses were not included because their seriousness tends to be either ambiguous or very minor and because the target population of the programs did not include status offenders.

Two stages of the procedure served to minimize skewness. First, the original responses in terms of frequencies were transformed to ten ordered categories. This provided distinctions along the full range of frequency without allowing extremely high rates to mask differences between low and moderate rates. Second, because the summary indices were still skewed, a logarithmic transformation was applied.

2. Status offenses were not included because the diversion programs were targeted at youths who had committed delinquent rather than status offenses. Furthermore, there was also a concern that charges for status offenses would be most easily influenced by the actions of justice personnel, service providers, and family members, and therefore might be confounded with treatment condition.

3. Lincoln et al. (1981) examined recidivism after controlling for postreferral selfreport delinquency, a procedure that would yield an analysis of differences in arrest rates not accounted for by delinquent behavior. Such analyses were also performed for the present study. The results were virtually identical to those for the recidivism analysis reported above, presumably because the groups did not differ on self-reported delinquency.

4. These measures were: self-reported delinquency, self-reported drug involvement, perceived stigma as delinquent, perceived stigma as emotionally disturbed, delinquency of peers, peers' disapproval of delinquency, parents' disapproval of delinquency, personal disapproval of delinquency, normlessness, importance of conventional goals, studentteacher relations, commitment to parents, and social isolation.

5. Prior arrests served as a covariate in the analysis for which it was not an independent variable. Analyses were also conducted without the covariates, with negligible impact on the findings.

\section{REFERENCES}

DUNFORD, F. W., D. W. OSGOOD, and H. F. WEICHSELBAUM (1981) National Evaluation of Diversion Projects: Final Report. Boulder, CO: Behavioral Research Institute. (National Criminal Justice Reference Service Microfiche NCJ 80830.) 
ELLIOTT, D. S. and S. S. AGETON (1980) "Reconciling race and class differences in self reported and official estimates of delinquency." Amer. Soc. Rev. 45 (February): 95-110.

-and R. J. CANTER (1979) "An integrated theoretical perspective on delinquent behavior." J. of Research Crime and Delinquency 16, 1: 3-27.

GOVE, W. [ed.] (1980) The Labelling of Deviance: Evaluating a Perspective (2nd ed). Beverly Hills, CA: Sage.

KLEIN, M. W. (1979) "Deinstitutionalization and diversion of juvenile offenders: a litany of impediments,"pp. 145-201 in N. Morris and M. Tonry (eds.) Crime and Justice: An Annual Review of Research, Vol I. Chicago, IL: University of Chicago Press.

LINCOLN, S. B., M. W. KLEIN, K. T. VAN DUSEN, and S. LABIN (1981) "Control organizations and labeling theory: official versus self-reported delinquency."Institute of Social Research, Indiana University. (unpublished)

LIPSEY, M. W., D. S. COR DRAY, and D. E. BERGER (1981) "Evaluation of a juvenile diversion program." Evaluation Rev. 5, 3: 283-306.

OSGOOD, D. W. and H. F. WEICHSELBAUM (forthcoming) "Juvenile diversion: when practice matches theory." J. of Research in Crime and Delinquency.

PALMER, T. and R. V. LEWIS (1980) An Evaluation of Juvenile Diversion. Cambridge, MA: Oelgeschlager, Gunn, and Han.

QUAY, H. C. and C. T. LOVE (1977) "The effects of a juvenile diversion program on rearrests." Criminal Justice and Behavior 4, 4: 377-395.

D. Wayne Osgood is Assistant Research Scientist at the Institute for Social Research of the University of Michigan, where he currently directs a study of peer influence in juvenile correctional institutions. He formerly served as Project Coordinator of the National Evaluation of Juvenile Diversion while at the Behavioral Research Institute, Boulder. 